\title{
Erratum to: Preventing Weight Gain and Obesity: Indirect Effects of the Family Check-Up in Early Childhood
}

\author{
Justin D. Smith • Zorash Montaño • Thomas J. Dishion •
}

Daniel S. Shaw $\cdot$ Melvin N. Wilson

Published online: 6 March 2015

(C) Society for Prevention Research 2015

Erratum to: Prev Sci

DOI 10.1007/s11121-014-0505-Z

Authors' Statement of Conflict of Interest Dr. Thomas J.

Dishion is the developer of the Family Check-up Program.

The online version of the original article can be found at $\mathrm{http}: / / \mathrm{dx} . \mathrm{doi} . \mathrm{org} /$ 10.1007/s11121-014-0505-z.

J. D. Smith $\cdot$ Z. Montaño $\cdot$ T. J. Dishion

REACH Institute, Arizona State University, Phoenix, AZ, USA

T. J. Dishion

Child and Family Center, University of Oregon, Eugene, OR, USA

D. S. Shaw

University of Pittsburgh, Pittsburgh, PA, USA

M. N. Wilson

University of Virginia, Charlottesville, VA, USA

J. D. Smith $(\triangle)$

Department of Psychology and Neuroscience, Baylor University, One Bear Place, Waco, TX, USA

e-mail: jd_smith@baylor.edu 